\title{
ОЦЕНКА НЕВРОЛОГИЧЕСКОГО ДЕФИЦИТА У БОЛЬНЫХ С ЦИАНОТИЧЕСКИМИ ТИПАМИ ВРОЖДЕННЫХ ПОРОКОВ СЕРДЦА В ДИНАМИКЕ ОПЕРАТИВНОГО ВМЕШАТЕЛЬСТВА
}

\author{
Нурмухамедова М.А.* \\ Ташкентский педиатрический медицинский институт, Ташкент, Узбекистан
}

Обследовано 97 больных от 7 до 14 лет с врожденными пороками сердца синего типа. Изучен неврологический статус больных, в том числе когнитивные и вегетативные функции, и определены превалирующие синдромы нарушения нервной системы. Установлено снижение когнитивных функций у больных с ВПС по сравнению с контролем до и после оперативного вмешательства. Вегетативная дизрегуляция проявлялась симпатикотонией, что ухудшает адаптационные возможности организма. Установлена взаимосвязь патологических изменений на компьютерной томограмме и электроэнцефалограмме у больных с нарушениями когнитивных функций.

Ключевые слова: врожденные пороки сердца, когнитивные функции, вегетативная нервная система.

Врожденные пороки сердца (ВПС) занимая третье место в структуре всех врожденных пороков развития, вносят существенный вклад в показатели перинатальной и младенческой смертности. Всё это в перспективе приводит к инвалидности детей, в итоге возрастают экономические затраты на хирургическую коррекцию и последующую реабилитацию детей-инвалидов $[1,2,3]$. Частота ВПС, по данным разных исследователей, колеблется от 4 до 17 на 1000 новорожденных [1,5,6,9]. В Англии этот показатель составляет 8 на 1000 детей, в США от 1,5 до 6 на 1000 детей [7]. В городе Ташкенте по данным Министерства Здравоохранения Республики Узбекистан пороки развития сердечно-сосудистой системы встречаются у 2,3 детей на 1000 родившихся [2].

Около 50\% детей с ВПС без своевременного оказания высококвалифицированной медицинской помощи погибают в периоде новорожденности и ещё 25\% - в первый год жизни $[1,4,5,10]$. В связи с налаженной работой скрининговых центров в Республике Узбекистан за последние 10 лет количество врожденных аномалий развития, в том числе и пороков развития сердца, сократилось в 1,7 раза [2].

Поражения нервной системы при врожденных пороках сердца всегда привлекали к себе внимание педиатров, кардиохирургов и невропатологов. По мнению большинства исследователей при ВПС цианотического типа об- наруживаются более многообразные изменения ЦНС, чем при пороках "белого" типа. Частота неврологических осложнений при этой патологии весьма вариабельна. По данным Бадалян Л.О. и соавторов (2001 г.) неврологические нарушения при ВПС наблюдаются у 25\% больных, тогда как в $15 \%$ случаев поражение головного мозга является основной причиной смерти больных с ВПС. Tyler H. R., Clark D. B. из 1875 больных с ВПС наблюдали приступы потери сознания и эпилептические припадки у $14,7 \%$ больных с цианозом и только у 3,1 \% больных без цианоза [11].

Известно, что недостаточность кровообращения отражается, прежде всего, на мозге - органе с высоким уровнем обменных процессов, наиболее чувствительном к недостатку кислорода. При цианотических формах ВПС наличие сброса венозной крови в артериальную или смешение крови ведут к увеличению объема циркулирующей крови в большом круге кровообращения и уменьшению в малом, что приводит к снижению насыщения крови кислородом (гипоксемии) и к появлению цианоза кожи и слизистых. Для улучшения доставки кислорода к органам и повышения эффективности вентиляции происходит развитие коллатерального кровообращения между сосудами большого и малого круга кровообращения. Перестройка коллатеральной сети кровообращения происходит в сосудах всех органов. Особенно это выражено в сосудах сердца, лег*e-mail: muhlisahon67@gmail.com 
ких и головного мозга. Благодаря компенсаторным механизмам состояние больного с цианотическими формами ВПС, несмотря на тяжелые нарушения гемодинамики, может быть длительно удовлетворительным, однако постепенно компенсаторные механизмы истощаются, длительная гиперфункция миокарда приводит к развитию тяжелых необратимых дистрофических изменений в сердечной мышце. Поэтому оперативное вмешательство при цианотических пороках показано в самом раннем детском возрасте [8,9,10].

Развитие искусственного кровообращения значительно расширило диапазон хирургических вмешательств и дало возможность коррекции большинства сложных врожденных и приобретенных пороков [6]. Между тем, несмотря на новейшие достижения в области кардиохирургии, остается высоким риск развития органических и функциональных нарушений на всех уровнях нервной системы в результате интраоперационного повреждения головного мозга вследствие гипоксии. В связи с этим актуальной задачей, попрежнему, остается изучение влияния различных пороков сердца на состояние неврологического статуса. Вопросы профилактики пов- реждения головного мозга во время операции на сердце с искусственным кровообращением, и развивающиеся после операции неврологические расстройства остаются открытыми [7,8].

В свете данной проблемы особый интерес представляет изучение неврологического статуса, в том числе состояние когнитивных функций и вегетативной нервной системы, до и после оперативного вмешательства, и поиск путей коррекции данных нарушений.

Цель работы. Изучить функциональное состояние вегетативной нервной системы и когнитивных функций у детей с цианотическими пороками сердца до и после оперативного вмешательства в период реабилитации сроком до 1 месяца.

Материал и методы исследования. Обследовано 97 детей в возрасте от 4 до 14 лет с цианотическими врожденными пороками сердца (триада и тетрада Фалло, болезнь Эбштейна, транспозиция магистральных сосудов) (таб. 1) до и после оперативного вмешательства на сердце с искусственным кровообращением. Из выборки были исключены дети с хромосомными аберрациями и аномалиями развития головного мозга.

Таблица 1

\section{Распределение детей по возрасту и формам врожденного порока}

\begin{tabular}{|l|c|c|c|c|c|}
\hline \multirow{2}{*}{ Формы пороков } & \multicolumn{2}{|c|}{$4-6$ лет } & \multicolumn{2}{c|}{$7-14$ лет } & \multirow{2}{*}{ Всего } \\
\cline { 1 - 5 } & мальчики & девочки & мальчики & девочки & \\
\hline Тетрада Фалло & $21(21,6 \%)$ & $13(13,4 \%)$ & $2(2,06 \%)$ & $7(7,2 \%)$ & $43(44,3 \%)$ \\
\hline $\begin{array}{l}\text { Транспозиция } \\
\text { магистральных } \\
\text { сосудов }\end{array}$ & $9(9,3 \%)$ & $7(7,2 \%)$ & - & - & $16(16,5 \%)$ \\
\hline Триада Фалло & $19(19,6 \%)$ & $14(14,4 \%)$ & $1(1,03 \%)$ & $2(2,06 \%)$ & $36(37,1 \%)$ \\
\hline $\begin{array}{l}\text { Болезнь } \\
\text { Эбштейна }\end{array}$ & $1(1,03 \%)$ & 1 & - & - & $2(2,06 \%)$ \\
\hline ИТОГО & $50(51,5 \%)$ & $35(36,1 \%)$ & $3(3,1 \%)$ & $9(9,3 \%)$ & $97(100 \%)$ \\
\hline
\end{tabular}

Примечание. В скобках указаны проценты

Всем детям проводилось исследование вегетативных функций включающее: определение исходного вегетативного тонуса согласно таблице Гийома-Вейна, вегетативная реактивность пробой Даньини-Ашнера, и вегетативная обеспеченность с помощью ортоклиностатической пробы. Для оценки уровня интеллектуального развития использовался дет- ский вариант методики Д. Векслера, где использовались адаптированные тесты для детей дошкольного (WPPSI) и школьного возраста (WISC) для узбекоязычных детей. Исследование проводили до хирургического вмешательства и через 1 месяц после оперативного вмешательства.

ЭЭГ регистрировали в покое, в состоянии 
физиологического бодрствования, также проводили компьютерную томографию головного мозга.

Группу контроля составили 20 практически здоровых детей аналогичного возраста.

Результаты и обсуждения. В ходе исследования у больных до операции были выявлены следующие синдромы: синдром пирамидной недостаточности, судорожный синдром, гиперкинетический и астеноневротический синдром (таб. 2).

Астеноневротические расстройства в виде головных болей, головокружения, слабости, быстрой утомляемости определялись у всех пациентов. Синдром пирамидной недостаточности определялась у $26(25,2 \%)$ больных и проявлялась в виде легкого гемипареза (положительный симптом Барре) центральным парезом VII и XII пар черепно-мозговых нервов, оживлением сухожильных рефлексов, расширением рефлексогенных зон пателлярного и ахиллового рефлексов, снижением брюшных рефлексов, появлением патологических рефлексов разгибательной группы (Бабинского, Оппенгейма и Гордона). У 6 $(6,2 \%)$ пациентов наблюдались стволовые глазодвигательные нарушения в виде диплопии, косоглазия. Судорожный синдром наблюдался у 32 больных (32,9\%), припадки но-

сили тонический характер у $13(13,4 \%)$ больных, тонико-клонический характер у $9(9,3 \%)$ больных, миоклонический характер у $6(6,2 \%)$ больных, а также полиморфные судорожные припадки отмечались у $4(4,1 \%)$ пациентов. Все припадки носили генерализованный характер с потерей сознания с постиктальной амнезией.

Гиперкинетический синдром имел место в 3 (3,1\%) случаях, где локальные миоклонические гиперкинезы определялись у $2(66,7 \%)$ пациентов и хореоатетоидные у 1 (33,3\%) пациента.

Исследование когнитивных функций до оперативного вмешательства показало снижение интеллектуальных показателей по невербальным субтестам в большей степени, чем по вербальным субтестам. Дети испытывали некоторое затруднение при выполнении тестов "Лабиринт", "Кодирование", "Складывание фигур", "Нахождение сходства", "Предложения", т.е. больше страдали память, внимание, пространственный анализ, и мыслительный процесс, проявляющийся в затруднении выполнения теста "Кубики Кооса". Следует отметить, что снижение интеллекта превалировало среди больных с судорожным синдромом.

Таблица 2 Показатели исследования когнитивных функций до вмешательства в среднем (оценка в баллах)

\begin{tabular}{|l|c|c|c|c|}
\hline \multirow{2}{*}{ Формы пороков } & \multicolumn{2}{|c|}{ До операции } & \multicolumn{2}{c|}{ После операции } \\
\cline { 2 - 5 } & $4-6$ лет & $7-14$ лет & $4-6$ лет & $7-14$ лет \\
\hline Пирамидный синдром & $76,4 \pm 2,4$ & $79,7 \pm 2,7$ & $72,4 \pm 2,6^{*}$ & $74,3 \pm 2,9^{*}$ \\
\hline $\begin{array}{l}\text { Астено-невротический } \\
\text { синдром }\end{array}$ & $78,7 \pm 2,7$ & $82,3 \pm 2,3$ & $79,6 \pm 2,4^{*}$ & $80,9 \pm 2,9 *$ \\
\hline $\begin{array}{l}\text { Гиперкинетический } \\
\text { синдром }\end{array}$ & $74,2 \pm 1,2^{*}$ & $71,8 \pm 1,8^{*}$ & $74,4 \pm 2,4^{*}$ & $72,9 \pm 1,9 *$ \\
\hline Судорожный синдром & $69,8 \pm 1,7^{*}$ & $70,2 \pm 1,2^{*}$ & $69,1 \pm 1,1^{*}$ & $70,3 \pm 1,3^{*}$ \\
\hline Группа контроля & $\mathbf{9 7 , 9 \pm 4 , 3}$ & $\mathbf{1 0 1 , 2 \pm 4 , 1}$ & $\mathbf{9 7 , 9 \pm 4 , 3}$ & $\mathbf{1 0 1 , 2 \pm 4 , 1}$ \\
\hline
\end{tabular}

Результаты достоверны относительно контрольных значений *-P<0,001.

Известно, что оперативные вмешательства, проводимые у детей с данной патологией, усугубляют гипоксическое состояние мозга, значимого для высокочувствительных центров надсегментарных структур вегетативной регуляции, что в свою очередь обуславливает неус- тойчивость гемодинамики и является одной из причин развития сердечно-сосудистой недостаточности с нарушением микроциркуляции [4].

Состояние когнитивной сферы в группе выборки до и после оперативного вмешательства показало следующие цифры (таб. 3): 
Показатели исследования когнитивных функций до вмешательства в среднем (оценка в баллах)

\begin{tabular}{|l|c|c|c|c|}
\hline \multirow{2}{*}{\multicolumn{1}{|c|}{ Формы пороков }} & \multicolumn{2}{|c|}{ До операции } & \multicolumn{2}{c|}{ После операции } \\
\cline { 2 - 5 } & $4-6$ лет & $7-14$ лет & $4-6$ лет & $7-14$ лет \\
\hline Тетрада Фалло & $73,4 \pm 2,3^{*}$ & $74,1 \pm 3,1^{*}$ & $72,1 \pm 2,1$ & $72,1 \pm 3,1$ \\
\hline $\begin{array}{l}\text { Транспозиция } \\
\text { магистральных сосудов }\end{array}$ & $76,9 \pm 3,1^{*}$ & $72,9 \pm 2,9^{*}$ & $74,7 \pm 2,9$ & $71,2 \pm 2,1$ \\
\hline Триада Фалло & $73,8 \pm 2,1^{*}$ & $71,9 \pm 1,6^{*}$ & $70,2 \pm 1,7^{*}$ & $70,8 \pm 1,4^{*}$ \\
\hline Болезнь Эбштейна & $70,1 \pm 1,9 *$ & - & $69,1 \pm 1,8^{*}$ & - \\
\hline Группа контроля & $\mathbf{9 7 , 9 \pm 4 , 3}$ & $\mathbf{1 0 1 , 2 \pm 4 , 1}$ & $\mathbf{9 7 , 9 \pm 4 , 3}$ & $\mathbf{1 0 1 , 2 \pm 4 , 1}$ \\
\hline
\end{tabular}

Результаты достоверны относительно контрольных значений *-Р<0,001.

Как видно из таб. 3, после операции показатели интеллекта были несколько снижены относительно первоначальных показателей, в большей степени отмечалось снижение внимания, пространственно-логического мышления. Данное состояние можно объяснить гипоксией головного мозга в результате длительного искусственного кровообра- щения и воздействием наркотических препаратов во время оперативного вмешательства.

В результате исследования исходного вегетативного тонуса у больных до операции определялась следующая картина - ваготония у $9(9,3 \%)$, симпатикотония у $65(67 \%)$, и у 23 $(23,7 \%)$ пациентов эйтония.

Таблица 4

\section{Состояние ВНС при ВПС (оценка в баллах)}

\begin{tabular}{|c|c|c|c|c|c|}
\hline \multirow[t]{2}{*}{ Показатель } & \multirow{2}{*}{ контроль } & \multicolumn{2}{|c|}{ 4-7 лет } & \multicolumn{2}{|c|}{ 8-14 лет } \\
\hline & & до & после & До & после \\
\hline $\begin{array}{l}\text { Вегетативная } \\
\text { реактивность (проба } \\
\text { Даньини-Ашнера) } \\
\end{array}$ & $-6,9 \pm 0,9$ & $-4,8 \pm 0,7^{*}$ & $-6,2 \pm 0,9^{\wedge}$ & $-2,9 \pm 0,5^{* *}$ & $-3,1 \pm 0,7^{\wedge}$ \\
\hline $\begin{array}{l}\text { Вегетативная } \\
\text { обеспеченность } \\
\text { (ортоклиностатичес-кая } \\
\text { проба) } \\
\text { реактивность ЧСС }\end{array}$ & $5,4 \pm 0,31 *$ & $4,8 \pm 0,8^{*}$ & $5,0 \pm 0,1^{\wedge}$ & $4,4 \pm 0,7 *$ & $2,7 \pm 0,9^{\wedge \wedge}$ \\
\hline реактивность АД & $4,8 \pm 0,3$ & $5,1 \pm 0,9$ & $5,9 \pm 0,6^{\wedge}$ & $5,2 \pm 0,8^{*}$ & $4,8 \pm 0,3^{\wedge}$ \\
\hline
\end{tabular}

Результаты достоверны относительно контрольных значений *-P<0,05, **-P<0,001.

Результаты достоверны относительно значений до операций ^^-P<0,05, ^^^-P<0,001.

Было выявлено, что у детей с ВПС характеристики вегетативных показателей в ближайшем послеоперационном периоде имели достоверные различия в зависимости от характера состояния ВНС в дооперационном периоде (табл 4). У больных с исходной симпатикотонией в дооперационном периоде отмечалось истощение симпатических влияний в постоперационном периоде, в то время как у больных с эйтонией и ваготонией отмечалось повышение симпатической активности, с последующим возвращением показателей к ис- ходным цифрам в течение 1-2 месяцев после операции.

В ходе анализа фонового ЭЭГ у больных были выявлены следующие изменения: у больных с судорожным синдромом на ЭЭГ отмечались характерные патологические изменения - выраженная ирритация $\alpha$-ритма с патологическими острыми волнами у 3 $(23,1 \%)$ пациентов, комплексов "спайк - волна" у 2 (15,3\%), комплексов "острая - медленная волна" и патологических острых волн у 8 $(61,6 \%)$ пациентов. У $23(23,7 \%)$ пациентов 
наблюдалась гиперсинхронизация биоритмов. У 27 (27,8\%) больных на ЭЭГ выявлена дисфункция срединных, мезэнцефальных структур головного мозга.

На компьютерной томограмме головного мозга были выявлены следующие изменения: расширение ликворных путей у 45 (46,4 \%) пациентов, кисты задней черепной ямки у 6 $(6,2 \%)$ пациентов, арахноидальная киста височной локализации у 4 (4,1\%) пациентов. Постинфарктные кисты размерами от 3 мм до 11 мм обнаруживались у $21(21,6 \%)$ больного с ВПС. Наряду с вышеперечисленными изменениями атрофия коры головного мозга была выявлена у $69(71,1 \%)$ пациентов. Следует отметить, что у 12 (12,4\%) больных с постишемическими и у 4 (4,1\%) больных с субарахноидальными кистами отмечались судорожные припадки.

Частота встречаемости нарушений функционального состояния ЦНС после операции в условиях общей анестезии, по данным Н.А.Шнайдера, А.Б.Салмина весьма вариабельна - от 2\% до 15\%-55\% и более. Механизм действия общих анестетиков реализуется на уровне центральных структур, преимущественно ретикулярной формации головного мозга, торможение которой приводит к снижению восходящего активирующего влияния на кору головного мозга. Неврологические осложнения при операциях на сердце в условиях искусственного кровообращения неизбежны, что обусловлено гипоксией в ходе операции. При этом данные изменения обусловлены хронической мозговой сосудистой недостаточностью [2]. Данные ЭЭГ исследований свидетельствуют о диффузных изменениях в центральной нервной системе с нарушением функций коры головного мозга и ме-

\section{ЛИТЕРАТУРА}

1. Алексахина Ю.А. Периоперационная оценка состояния головного мозга у больных с ишемической болезнью сердца, оперированных в условиях ИК// Дисс. канд.мед.наук.- М., 2003.- 130 с.

2. Атамурадов Ш.И., Хакимова Д.Т., Рустамова Х.Е. Характеристика инвалидности детей с врожденными пороками сердца // Мед. журнал Узбекистана, -2000,№ 4,- С. 84-86.

3. Никулин Н. Л. Влияние гипотермической защиты и зо-диэнцефальных структур [2].

Результаты наших исследований показали, что у детей с ВПС симптомы неврологических расстройств связаны гемодинамическими изменениями головного мозга и проявляются различными симптомами поражения нервной системы, где отмечается превалирование судорожного синдрома в $32,9 \%$ случаев, синдромов пирамидной недостаточности в $25,2 \%$ и гиперкинетического в $3,1 \%$ и астено-невротического синдрома в $38,8 \%$ случаях. В результате интраоперационной гипоксии головного мозга, обусловленной искусственным кровообращением, отмечается снижение интеллектуальных показателей и изменение вегетативной направленности, что требует разработки комплекса лечебных мероприятий, направленных на профилактику и устранение данных нарушений.

\section{Выводы}

1. У пациентов с цианотическими формами ВПС в неврологическом статусе наблюдается превалирование синдрома пирамидной недостаточности, гиперкинетического, судорожного и астеноневротического синдромов.

2. Гемодинамические нарушения головного мозга у детей с ВПС во время оперативного вмешательства приводит к когнитивным расстройствам в виде снижение памяти и внимания, пространственного анализа и мыслительных функций, что обусловлено гипоксией головного мозга в результате длительного искусственного кровообращения и воздействием наркотических препаратов.

3. Вегетативные нарушения при цианотических формах ВПС проявляются симпатикотонией, что обуславливает истощаемость адаптационных возможностей организма в послеоперационном периоде.

хирургического вмешательства на вариабельность частоты сердечных сокращений у детей с врожденными пороками сердца: Автореф. дис. ... канд. мед. наук. Казань, 2000.

4. Таболин В. А. и др. Актуальные проблемы перинатальной кардиологии // Журн. Педиатрия .,- 2000.- № 5.C. 23

5. Черкасов Н. С. Заболевания сердца у новорожденных и детей раннего возраста.- Ростов, 2006.- С. 5-41. 
6. David Wypij, PhD. Jane W. Newburger, MD et al. The effect of duracion of Deep hypothermic circulatjry arrest in infant heart surgery on lateneurodevelopment: The Boston Circulatory Arrest Trial // J. Thorac. Cardiov. Surg. 2003. Vol. 126. P. 13971403.

7. Georgiadis D, VL, Antonia Hempel, Ralf W et.al. Doppler microembolic signals during cardiac surgery: Comparison between arterial line and middle cerebral artery. J. Thorac. Cardiov. Surg. 2003. Vol. 126. P. 1638 1639.

8. Marek P. Ehrlich, MD. Jock McCullough, MD et al. Cerebral effects of cold reperfusion after hypothermic circulatory arrest // J. Thorac. Cardiovas. Surg. 2001. Vol.
121. P. 923-931.

9. Menache C.C., Adre J. du Plessis, Wessel D.L.,Jonas R.A.,Newburger J.W. Current incidence of acute neurologic Complications After Open Heart Operacions in Children // Ann. Thorac Surg. 2002. Vol. 73. P. 1752 -1758. 10. Pigula F.A., Nemoto E.M., Griffith B.P.,Siewers R.D.// Regional low flow perfusion provides cerebral circulatory support during neonatal aortic arch reconstruction// Thorac. Cardiovasc. Surg. 2000 Feb; 119 (2). P. 331 $-9$.

11. Tyler H. R., Clark D. B. Cerebrovascular accidents in patients with congenital heart disease - "Arch. Neurol. Psychiat.", 1997, v. 77, p. 383-389.

\title{
XÜLASə
}

\section{CORRAHİ MÜDAXILə DINAMIKASINDA ANADANGəLMӘ ÜRӘK QÜSURLARININ SIANOTIK TIPI ILə XəSTəLӘRDӘ NEVROLOJI DEFISITIN QIYMMTLONDIRILMӘSI}

\author{
Nurmuxamedova M.A. \\ Daşkənt pediatrik tibb institutu, Daşkənd, Özbəkistan
}

7-14 yaşlı sianotik tip anadangəlmə ürək qüsurlu 97 xəstə tədqiqata cəlb edilmişdir. Xəstələrin nevroloji statusu, o cümlədən koqnitiv və vegetativ funksiyalar öyrənilmişdir və sinir sisteminin pozulmasının daha çox rast gəlinən sindromaları təyin edilmişdir. Anadangəlmə ürək qüsuru olan xəstələrin kontrol qrupla müqayisədə cərrahi müdaxilədən əvvəl və sonra koqnitiv funksiyalarının zəifləməsi aşkarlanmışdır. Vegetativ dizrequlyasiya simpatikotoniya ilə özünü göstərmişdir ki, bu da orqanizmin adaptasion imkanlarının aşağı salır. Koqnitiv funksiyaların pozulması olan xəstələrdə patoloji dəyişikliklərin kompyüter tomoqramma və elektroensefaloqrafiyadakı dəyişikliklərlə əlaqəsi təyin edilmişdir.

Açar sözlər: anadangəlmə ürək qüsurları, koqnitiv funksiyalar, vegetativ sinir sistemi.

\section{SUMMARY}

\section{DYNAMICS OF NEUROLOGICAL DEFICIENCY BEFORE AND AFTER SURGICAL OPERATIONS ON CYANOTIC CONGENITAL HEART DISEASES}

\author{
Nurmuxamedova M.A. \\ Tashkent Pediatric Medical Institute, Tashkent, Uzbekistan
}

97 patients at age from 7 to 14 years with congenital heart diseases of blue type surveyed. The neurologic status of patients, including cognitive and vegetative functions studied, and prevailing syndromes of disturbance of nervous system are defined. Depression of cognitive functions at patients with CHD in comparison with control before and after an operative measure is established. The vegetative dysregulation was shown by a sympaticotonia that worsens adaptic possibilities of an organism. The interrelation of pathological changes on the computer tomogramm and an electroencephalogram at patients with disturbances of cognitive functions established.

Key Words: congenital heart diseases, cognitive functions, vegetative nervous system. 